\title{
Potássio no solo em conseqüência da adubação sobre a palha de milheto e chuva simulada
}

\author{
Ciro Antonio Rosolem ${ }^{(1)}$, Fernanda Pereira dos Santos ${ }^{(1)}$, José Salvador Simonetti Foloni(2) \\ e Juliano Carlos Calonego ${ }^{(1)}$
}

\begin{abstract}
(1)Universidade Estadual Paulista, Faculdade de Ciências Agronômicas, Dep. de Produção Vegetal, Caixa Postal 237, CEP 18603-970 Botucatu, SP. E-mail: rosolem@fca.unesp.br, fpsantos@fca.unesp.br, jcalonego@fca.unesp.br (2)Universidade do Oeste Paulista, Dep. de Fitotecnia, Rod. Raposo Tavares, Km 572, CEP 19067-175 Presidente Prudente, SP. E-mail: sfoloni@unoeste.br
\end{abstract}

\begin{abstract}
Resumo - O objetivo deste trabalho foi avaliar a lixiviação de potássio (K), no solo, e sua presença nas formas trocável e não trocável, em conseqüência da aplicação de chuva simulada e adubação potássica sobre palha de milheto, na superfície do solo. Vasos com terra e palha de milheto na superfície (quantidade equivalente a $8 \mathrm{th} \mathrm{ha}^{-1}$ ) receberam ou não adubação potássica, na dose de $150 \mathrm{~kg} \mathrm{ha}^{-1} \mathrm{de} \mathrm{K}_{2} \mathrm{O}$, na forma de $\mathrm{KCl}$, aplicados sobre a palha. Na seqüência, foram aplicadas lâminas de água de 0 a $50 \mathrm{~mm}$. O solo foi analisado em diversas profundidades, quanto aos teores de K trocável e não trocável. A palha do milheto revelou-se fonte importante de K, que é lixiviado até $4 \mathrm{~cm}$ de profundidade por chuvas superiores a $30 \mathrm{~mm}$. A lixiviação de $\mathrm{K}$, em profundidade no solo, é proporcional à chuva aplicada; entretanto, uma chuva de $50 \mathrm{~mm}$ não carreia o nutriente para profundidades superiores a $8 \mathrm{~cm}$. A passagem de K trocável para não trocável é rápida, conforme atestado pelo conteúdo de K não trocável na camada de solo abaixo de $4 \mathrm{~cm}$.
\end{abstract}

Termos para indexação: Pennisetum americanum, lixiviação de K, K trocável, K não trocável, sistema de semeadura direta.

\section{Soil potassium as affected by fertilization over the millet straw and simulated rain}

\begin{abstract}
This research aimed to evaluate K leaching through the soil profile, and its presence in the exchangeable and nonexchangeable forms, as affected by simulated rain and potassic fertilizer applied over the pearl millet straw left on soil surface. Pots filled with soil and pearl millet straw (equivalent to $8 \mathrm{t} \mathrm{ha}^{-1}$ ) in the surface received or not $150 \mathrm{~kg} \mathrm{ha}^{-1}$ of $\mathrm{K}_{2} \mathrm{O}$, as $\mathrm{KCl}$ applied over the straw. Rainfalls from 0 to $50 \mathrm{~mm}$ were applied. The soil was analyzed at several depths for exchangeable and nonexchangeable K. Pearl millet straw acts as an important $\mathrm{K}$ source, which is leached down to $4 \mathrm{~cm}$ depth when subjected to a simulated 30-mm rain. $\mathrm{K}$ leaching is positively related to the amount of rain; however, a 50-mm rain does not lead the nutrient down to more than $8 \mathrm{~cm}$ depth. The transformation of exchangeable $\mathrm{K}$ to non exchangeable $\mathrm{K}$ is very fast, as shown by the contents of non exchangeable $\mathrm{K}$ in the soil profile down to $4 \mathrm{~cm}$.
\end{abstract}

Index terms: Pennisetum americanum, $\mathrm{K}$ leaching, exchangeable K, nonexchangeable $\mathrm{K}$, no-till.

\section{Introdução}

O potássio é o segundo nutriente mineral requerido em maior quantidade pelas espécies vegetais, depois do $\mathrm{N}$, e tem alta mobilidade na planta, em qualquer concentração, seja dentro da célula, no tecido vegetal, no xilema ou no floema. Esse nutriente não é metabolizado na planta e forma ligações com moléculas orgânicas de fácil reversibilidade, além de ser o íon mais abundante nas células vegetais (Marschner, 1995). Assim, as quantidades de $\mathrm{K}$ na parte aérea de plantas de cobertura podem constituir uma fonte expressiva do nutriente para culturas subseqüentes, no sistema de semeadura direta; e a mineralização do K da palha, depositada na superfície do solo, pode ser relativamente rápida, pois esse nutriente permanece quase que totalmente na forma iônica, dentro do tecido vegetal. O potássio do solo, por sua vez, é formado pelo $\mathrm{K}$ da solução, o K trocável, o K não trocável (fixado) e o K estrutural, e o suprimento de K para as plantas advém da solução e dos sítios de troca dos colóides do solo, que estão em equilíbrio com o K não trocável e com o $\mathrm{K}$ estrutural dos minerais (Sparks \& Huang, 1985). 
A ação da água das chuvas, independentemente da decomposição da matéria orgânica, pode constituir um fator importante na lixiviação de nutrientes de restos vegetais. Nos trabalhos de Silva \& Ritchey (1982) e Klepker \& Anghinoni (1995), constatou-se aumento nos teores de $\mathrm{K}$ do solo, próximo à base dos caules do milho, em razão da lavagem do nutriente da parte aérea das plantas senescentes, no final do ciclo da cultura. Rosolem et al. (2003) submeteram restos vegetais de seis espécies de plantas de cobertura a diferentes quantidades de chuva simulada e observaram que essas palhas podem fornecer ao solo uma quantidade considerável de $\mathrm{K}$, de $7 \mathrm{a} 24 \mathrm{~kg} \mathrm{ha}^{-1}$, sob um volume de chuva acumulada de $70 \mathrm{~mm}$, sem que houvesse decomposição da palha.

O potássio disponibilizado da palha, assim como aquele adicionado via adubação potássica, podem ser intensamente lixiviados no perfil do solo, dependendo da quantidade de chuva, da dose de nutriente aplicado e da textura do solo, entre outros fatores, o que faz com que o manejo da adubação potássica seja importante, do ponto de vista econômico e ambiental. Rosolem \& Nakagawa (2001) observaram que a lixiviação de K, no perfil de um solo de textura média, aumentou muito, quando foram aplicadas doses de $\mathrm{K}_{2} \mathrm{O}$ acima de $80 \mathrm{~kg} \mathrm{ha}^{-1}$ por ano, independentemente do modo de aplicação do fertilizante. A liberação de ácidos orgânicos pela palha da superfície do solo altera a ordem de lixiviação de cátions no solo e permite um acúmulo de $\mathrm{K}$ nas primeiras camadas, em sistemas com semeadura direta, com maior lixiviação cátions divalentes ou trivalentes (Franchini et al., 1999; Ziglio et al., 1999).

Considerando-se: que as altas produtividades que vêm sendo obtidas demandam altas doses de fertilizante potássico; que a própria palha pode fornecer ao solo quantidades consideráveis do nutriente; e, ainda, que o sistema de produção em semeadura direta altera a química do solo, de modo a modificar a lixiviação de cátions, é importante o conhecimento do comportamento do K aplicado sobre a palha deixada na superfície do solo.

O objetivo deste trabalho foi avaliar o aporte e a lixiviação de K no solo, assim como sua presença nas formas trocável e não trocável, em conseqüência da aplicação de lâminas de água, por meio de chuva simulada e adubação potássica, sobre a palha de milheto deixada na superfície.

\section{Material e Métodos}

O experimento foi realizado em condições controladas, casa de vegetação e simulador de chuva, na Fac. de Ciências Agronômicas, na Universidade Estadual Paulista, em Botucatu, SP, nos anos de 2003 e 2004. Utilizou-se uma porção de solo, classificado como Latossolo Vermelho distroférrico de textura média (Embrapa, 1999), coletado na profundidade de 0-20 cm em área que vinha sendo cultivada com milho; depois da secagem ao ar, a amostra foi passada em peneira com malha de $4 \mathrm{~mm}$. A terra, que foi homogeneizada e analisada quimicamente (Raij et al., 2001), apresentou: $\mathrm{pH}\left(\mathrm{CaCl}_{2}\right)$ de 4,4; $23 \mathrm{mg} \mathrm{dm}^{-3}$ de MO; $6 \mathrm{mg} \mathrm{dm}^{-3}$ de P (resina); e 27,0, 0,8, 8,0 e 4,0 $\mathrm{mmol}_{\mathrm{c}} \mathrm{dm}^{-3}$ de $\mathrm{H}^{+}+\mathrm{Al}^{3+}, \mathrm{K}^{+}, \mathrm{Ca}^{2+} \mathrm{e} \mathrm{Mg}^{2+}$, respectivamente. A análise granulométrica (Embrapa, 1997) mostrou $640 \mathrm{~g} \mathrm{~kg}^{-1}$ de areia, $80 \mathrm{~g} \mathrm{~kg}^{-1}$ de silte e $280 \mathrm{~g} \mathrm{~kg}^{-1}$ de argila. Aplicou-se calcário dolomítico $(\mathrm{CaO}=28 \% ; \mathrm{MgO}=20 \%$ e PRNT $=95 \%)$, para elevar a saturação por bases a 70\% (Raij et al., 1996). Depois da calagem, a terra foi umedecida à capacidade de campo e acondicionada em sacos de plástico por 30 dias. Em seguida, a terra foi secada ao ar e adubada com $100 \mathrm{mg} \mathrm{dm}^{-3}$ de $\mathrm{N}$ (uréia) e $200 \mathrm{mg} \mathrm{dm}^{-3}$ de $\mathrm{P}$ (superfosfato simples). Parte da terra corrigida e adubada com $\mathrm{N}$ e $\mathrm{P}$ recebeu $150 \mathrm{mg} \mathrm{dm}^{-3}$ de $\mathrm{K}$ (cloreto de potássio) e foi utilizada para o cultivo de milheto (Pennisetum americanum var. BN-2), em vasos de $12,5 \mathrm{dm}^{3}$. $O$ restante da terra, que não recebeu adubação potássica, foi reservado para a montagem das colunas de solo utilizadas no processo de simulação de chuva.

O milheto foi semeado em 10/12/2003. Depois da emergência, fez-se um desbaste, deixandose 25 plantas por vaso. A temperatura da casa de vegetação foi mantida a $20-30^{\circ} \mathrm{C}$, durante todo o período de cultivo. Do 20 으 ao 30 ia depois da emergência do milheto, foram feitas adubações suplementares nos vasos, por meio da água de irrigação, com macro e micronutrientes, num total de 100 , 50, 50, 25, 25 e 53,3 $\mathrm{mg} \mathrm{dm}^{-3}$ de N, P, K, Ca, Mg e $\mathrm{S}$, respectivamente, com os sais $\mathrm{NH}_{4} \mathrm{NO}_{3}$, $\mathrm{NH}_{4} \mathrm{H}_{2} \mathrm{PO}_{4}, \quad \mathrm{KNO}_{3}, \mathrm{CaSO}_{4}$ e $\mathrm{MgSO}_{4}$. Os micronutrientes adicionados foram $\mathrm{B}, \mathrm{Zn}, \mathrm{Mo}, \mathrm{Mn}$ e $\mathrm{Cu}$, na dose de $1 \mathrm{mg} \mathrm{dm}^{-3}$, por meio das fontes $\mathrm{H}_{3} \mathrm{BO}_{3}, \mathrm{ZnCl}_{2}, \mathrm{H}_{2} \mathrm{MoO}_{4}, \mathrm{MnCl}_{2}$ e $\mathrm{CuCl}_{2}$. 
Aos 50 dias depois da emergência, as plantas de milheto foram dessecadas com glifosato (i.a.) em dose equivalente a $1,64 \mathrm{~kg} \mathrm{ha}^{-1}$.

As colunas com o solo peneirado, corrigido e adubado com $\mathrm{N}$ e P, que foram utilizadas na simulação de chuva, foram montadas com anéis de PVC rígido, sobrepostos, com $20 \mathrm{~cm}$ de diâmetro interno, correspondentes às seguintes camadas: $0-2,2-4,4-8,8-16$ e $16-32 \mathrm{~cm}$. A terra foi acondicionada nos vasos à densidade de $1,2 \mathrm{~g} \mathrm{~cm}^{-3}$, correspondente à do solo no campo. Para acomodar a terra nas colunas, fizeram-se irrigações seqüenciais até a capacidade de campo, durante alguns dias, até que não houvesse mais redução de volume da terra dentro das colunas. Foram colocados anéis com $5 \mathrm{~cm}$ de altura e $20 \mathrm{~cm}$ de diâmetro, sobre a superfície da terra das colunas, para acomodar a palha de milheto durante o processo de simulação de chuva. Os anéis foram unidos com fita plástica adesiva, e as colunas foram vedadas ao fundo com material de plástico impermeável.

Dez dias depois da dessecação do milheto, a parte aérea das plantas foi coletada, picada em pedaços de 2 a $5 \mathrm{~cm}$ e secada em estufa de aeração forçada a 30ㅡㅡ, por 48 horas. Depois da desidratação, a palha foi acondicionada em sacos de plástico e mantida sob refrigeração a $2^{\circ} \mathrm{C}$, para posterior utilização no processo de simulação de chuva. Retiraram-se amostras dessa palha para nova secagem a $60^{\circ} \mathrm{C}$, por 72 horas em estufa de aeração forçada, que serviram para aferir a quantidade de palha seca a $30{ }^{\circ} \mathrm{C}$ a ser acomodada na superfície do solo das colunas, equivalente a uma cobertura do solo de $8 \mathrm{t} \mathrm{ha}^{-1}$ de material vegetal secado a $60^{\circ} \mathrm{C}$.

Sobre a palha do milheto, antes da simulação de chuva, em parte dos vasos, de acordo com o delineamento experimental, aplicaram-se doses de cloreto de potássio granulado equivalentes a $150 \mathrm{~kg} \mathrm{ha}^{-1} \mathrm{de}_{2} \mathrm{O}$, misturadas com areia lavada.

O simulador de chuvas utilizado no experimento foi descrito detalhadamente por Silva (2000). Foi utilizada a barra de suporte dos bicos de alta vazão Spray System, modelo TK-SS-20, com o espaço entre bicos de 0,50 m. O equipamento foi calibrado para aplicar um volume de água equivalente a $2,5 \mathrm{~mm}$ a cada passagem, operando à pressão de trabalho de $81 \mathrm{~Pa}$, com velocidade de deslocamento da barra de $0,0925 \mathrm{~m} \mathrm{~s}^{-1}$.
As quantidades de chuva aplicadas foram de 0,10 , 20, 30, 40 e 50 mm de lâmina de água, equivalentes a 4, 8, 12, 16 e 20 deslocamentos da barra de aplicação.

Depois da simulação de chuva, as colunas de PVC com a terra e a palha foram mantidas por cinco dias, à temperatura ambiente, para estabilização da lixiviação da água. Depois desse período, as colunas foram desmontadas, a palha foi separada, e porções de solo foram coletadas nas camadas de 0-2, 2-4, 4-8, 8-16 e 16-32 cm de profundidade. Em seguida, o solo foi secado em estufa de aeração forçada a $40^{\circ} \mathrm{C}$ por 48 horas e, posteriormente, passado em peneira com $2 \mathrm{~mm}$ de malha.

O potássio trocável das amostras de solo foi determinado pelo método da resina trocadora (Raij et al., 2001), e o K não trocável das mesmas amostras foi extraído com $\mathrm{HNO}_{3} 1,0 \mathrm{~N}$ a quente (Knudsen et al., 1982).

Amostras da palha de milheto foram coletadas depois da simulação de chuva, secadas em estufa de aeração forçada a $60^{\circ} \mathrm{C}$ por 72 horas, e moídas para determinação dos teores de $\mathrm{K}$ no tecido vegetal, conforme Malavolta et al. (1997).

O experimento foi delineado em blocos ao acaso, num esquema fatorial $6 \times 2$, com quatro repetições. Os tratamentos constituíram-se de seis lâminas de água $(0,10,20,30,40$ e $50 \mathrm{~mm})$, e ausência e presença de adubação potássica (0 e $150 \mathrm{~kg} \mathrm{ha}^{-1}$ de $\mathrm{K}_{2} \mathrm{O}$ ).

Os resultados originais dos teores e acúmulo de $\mathrm{K}$ na palha de milheto e de K trocável e não trocável, em cada camada do solo, foram submetidos à análise de variância. Foram ajustadas as equações de regressão, para expressar o comportamento do $\mathrm{K}$ da palha, assim como do K trocável e não trocável do solo, resultado das lâminas de água aplicadas, para os tratamentos com e sem adubação potássica. Foram aceitas equações significativas até $5 \%$ de probabilidade pelo teste $\mathrm{F}$, com o maior coeficiente de determinação $\left(\mathrm{R}^{2}\right)$, de acordo com procedimentos descritos por Mischan \& Pinho (1996).

\section{Resultados e Discussão}

Na Figura 1, estão descritos os teores e as quantidades de K na palha de milheto, com adubação e sem adubação potássica, em conseqüência da lâmina de água aplicada via chuva simulada. É importante lembrar que a palha foi analisada sem lavagem, uma vez que este procedimento extrairia K dela (Rosolem et al., 2003). 
Assim, sem chuva simulada, a quantidade de $\mathrm{K}$ verificada na palha é oriunda da própria palha e do adubo. Entretanto, uma chuva de $10 \mathrm{~mm}$ foi suficiente para lavar praticamente todo o $\mathrm{K}$ do fertilizante retido nos restos vegetais da planta de cobertura, e a partir de $30 \mathrm{~mm}$ de precipitação, a disponibilização do nutriente, com adubação e sem adubação, mantevese constante (Figura 1). Portanto, uma quantidade de chuva relativamente baixa para condições de verão tropical (30 mm) lixiviou 149 e $67 \mathrm{~kg} \mathrm{ha}^{-1}$ de $\mathrm{K}$ das palhas com adubação e sem adubação potássica, respectivamente, mesmo considerando-se que os restos vegetais do milheto, do presente trabalho, permaneceram na superfície do solo por cinco dias, em temperatura ambiente, depois da aplicação de chuva, propiciando algum grau de decomposição biológica.

Nos trabalhos de Rosolem et al. (2003, 2005), as máximas lixiviações de $\mathrm{K}$ da palha de milheto ocorreram com chuvas em torno de $30 \mathrm{~mm}$, sem que houvesse decomposição biológica do material vegetal, mesmo em condições em que as plantas receberam adubações relativamente altas de $\mathrm{KCl}$, que propiciaram concentrações elevadas do nutriente na palha.

Espera-se que a taxa de mineralização dos nutrientes contidos nos restos vegetais, deixados na superfície do solo no sistema de semeadura direta, de maneira geral, seja semelhante à taxa de decomposição da matéria orgânica. Porém, o K é exceção, pois este nutriente é totalmente liberado no solo, mesmo sem haver decomposição completa do tecido vegetal. De acordo com Marschner (1995), o K apresenta alta mobilidade na planta e não é metabolizado, encontrando-se quase que totalmente na forma de íon, nas células vegetais. Ou seja, o K é um nutriente absorvido em quantidades relativamente altas pelas plantas e não é constituinte estrutural de moléculas e tecidos, o que o torna passível de ser extraído com relativa facilidade da cobertura morta, sem haver, necessariamente, decomposição e mineralização biológicas.

Em trabalhos desenvolvidos por Silva \& Ritchey (1982) e Klepker \& Anghinoni (1995), observou-se a formação de gradientes de concentração de K trocável no solo, transversais às linhas de semeadura do milho, com altas concentrações de K, próximas à base dos caules das plantas, que diminuíram, gradativamente, até o meio das entrelinhas, independentemente do modo de aplicação do fertilizante potássico e dos sistemas de preparo de solo estudados; tais concentrações elevadas de K no solo próximo às plantas justificaram-se em razão da lavagem deste nutriente na parte aérea do milho, pela água das chuvas, no final do ciclo da cultura.
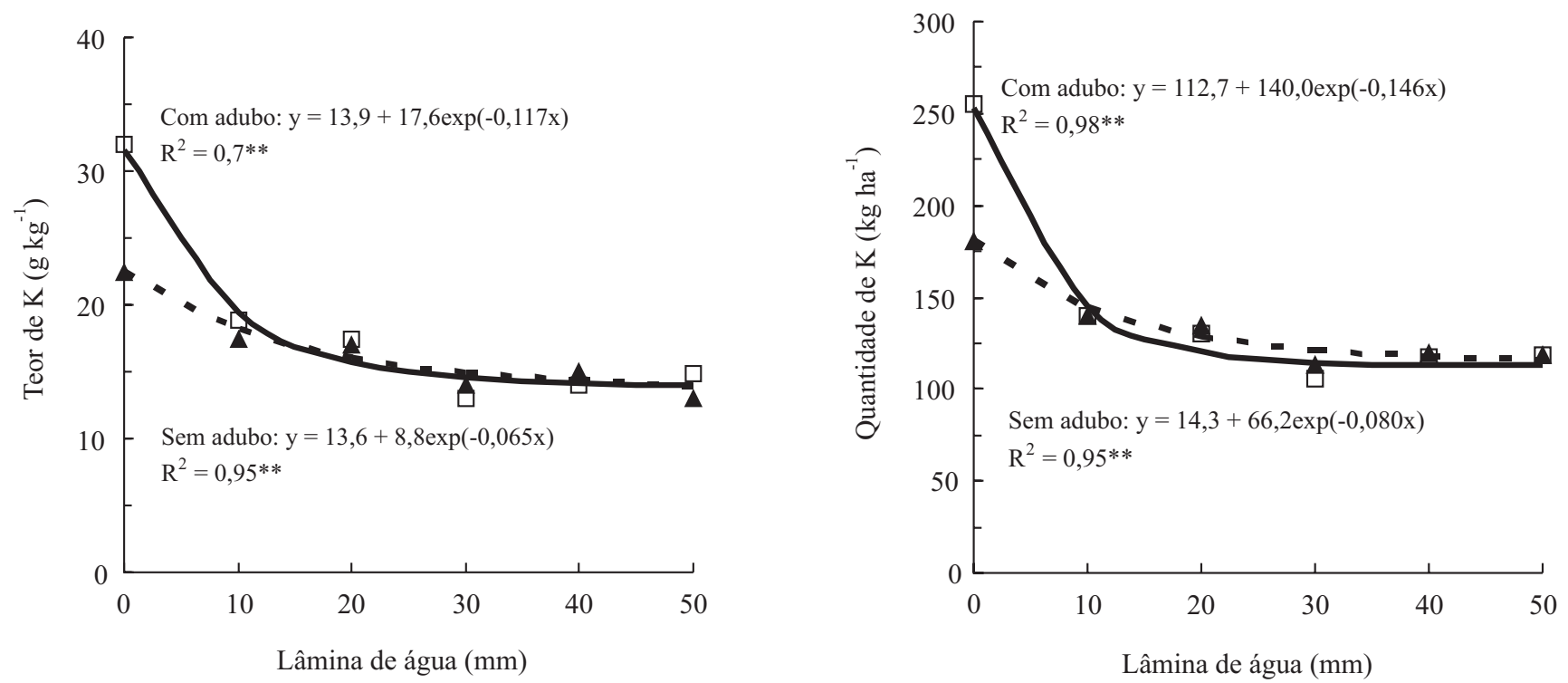

Figura 1. Teor e quantidade de potássio na palha de milheto, resultantes da adubação potássica com 150 kg ha-1 de $\mathrm{K}_{2} \mathrm{O}$ e da lâmina de água aplicada como chuva simulada. **Significativo a 1\% de probabilidade. 
Rosolem et al. (2003) submeteram à simulação de chuva os restos vegetais de aveia preta, milheto, sorgo, crotalária juncea, braquiária e triticale, e observaram concentrações de K consideráveis na água percolada, com valores que variaram de 7 a $24 \mathrm{~kg} \mathrm{ha}^{-1}$ de $\mathrm{K}$ lixiviado, de uma cobertura equivalente a $8 \mathrm{t} \mathrm{ha}^{-1}$ de matéria seca de palha, com lâminas acumuladas de $70 \mathrm{~mm}$, sem que houvesse decomposição do material vegetal.

O teor de K trocável nas camadas de solo, em conseqüência da chuva simulada aumentou consideravelmente, até $4 \mathrm{~cm}$ de profundidade, e teve origem na palha do milheto, uma vez que estes vasos não receberam adubação potássica (Figura 2). De acordo com os resultados da Figura 1, a palha do milheto contribuiu com mais de $60 \mathrm{~kg} \mathrm{ha}^{-1}$ de K para o solo, que foi lixiviado até a camada de 2-4 cm (Figura 2). Mesmo uma chuva de $50 \mathrm{~mm}$ não foi suficiente para carrear o K abaixo de $4 \mathrm{~cm}$ no solo, quando não foi aplicado fertilizante.

É interessante notar que mesmo o K normalmente considerado como não trocável foi modificado até a profundidade de $4 \mathrm{~cm}$ (Figura 2). Rosolem et al. (1993) haviam relatado que a passagem do $\mathrm{K}$ de formas trocáveis para não trocáveis era rápida, principalmente em solos esgotados, como parece ser o caso, considerando-se os baixos teores de K trocável e teores mais altos de K não trocável, em algumas profundidades (Rosolem \& Nakagawa, 2001). Este fato deve ter influenciado na lixiviação do nutriente, restringindo-a, pois de outra forma, haveria mais K passível de lixiviação, na solução.

Na condição de adubação potássica a lanço, sobre a palha de milheto, o K trocável e o K não trocável variaram intensamente, nos primeiros $8 \mathrm{~cm}$ de profundidade do solo, com o aumento da quantidade de chuva (Figura 3). As quantidades de K encontradas no solo com adubação foram muito superiores àquelas determinadas na ausência de adubação, quando a única fonte do nutriente foi a palha do milheto. Nas camadas até $4 \mathrm{~cm}$ de profundidade, parece ter ocorrido saturação dos sítios de retenção do K, uma vez que as curvas atingem o máximo, mesmo no caso do K não trocável. Assim, o K que fica na solução do solo é passível de lixiviação às camadas mais profundas. Isso aparece na Figura $3 \mathrm{C}$, profundidade de $4-8 \mathrm{~cm}$, onde verifica-se resposta linear dos teores de K trocável e não trocável, com o aumento da lâmina de água da chuva simulada aplicada.
Neste trabalho, foi utilizado um Latossolo Vermelho distroférrico de textura média, grau de intemperismo e permeabilidade relativamente elevados, o que justifica a lixiviação de $\mathrm{K}$, principalmente na condição de aplicação de $\mathrm{KCl}$ sobre a palha. No entanto, a fixação de K pelos colóides do solo deveria ter sido baixa ou inexpressiva, por este solo apresentar baixos teores de argilas silicatadas (Carvalho et al., 1983). Os incrementos do K não trocável foram significativos, nos primeiros $8 \mathrm{~cm}$ de profundidade do solo que recebeu adubação potássica, mostrando que parte do K adicionado via fertilizante é retido no solo além da capacidade de troca catiônica dos colóides, o que reduz, de certa forma, as perdas por lixiviação (Figura 3).

Segundo Sparks \& Huang (1985), o K do solo é formado pelo $\mathrm{K}$ da solução, o K trocável, o K não trocável (fixado) e o K estrutural, e as proporções do K total do solo, correspondentes ao K da solução e ao K trocável, são relativamente pequenas. O suprimento de K para as plantas advém da solução e dos sítios de troca dos colóides do solo, que estão em equilíbrio com o K não trocável e com o K estrutural dos minerais. De acordo com Raij (1996), nos solos da grande maioria das regiões tropicais do Brasil, os colóides são formados predominantemente por matéria orgânica, caulinita e óxidos de ferro e alumínio, e o K trocável, nestas condições de pedogênese, representa a porção mais importante disponível às plantas. Contudo, admitem que o K não trocável do solo e o $\mathrm{K}$ dos restos vegetais podem contribuir consideravelmente, para a nutrição das plantas cultivadas.

No padrão de lixiviação de K no solo, chuvas de até $50 \mathrm{~mm}$ lixiviaram o nutriente, no máximo, até a camada de 4-8 cm. Esta é, normalmente, a camada onde se inicia o desenvolvimento radicular das plantas. Assim, tanto o $\mathrm{K}$ da palha que estava em superfície quanto o $\mathrm{K}$ do adubo aplicado a lanço sobre a palha foram transportados para o solo e permaneceram numa camada acessível às raízes das plântulas. Isso indica a viabilidade da aplicação do adubo potássico a lanço, em que o K estaria, depois das primeiras chuvas, disponível na região de crescimento radicular, sem, no entanto, prejudicar a população de plantas em razão da alteração da salinidade. 

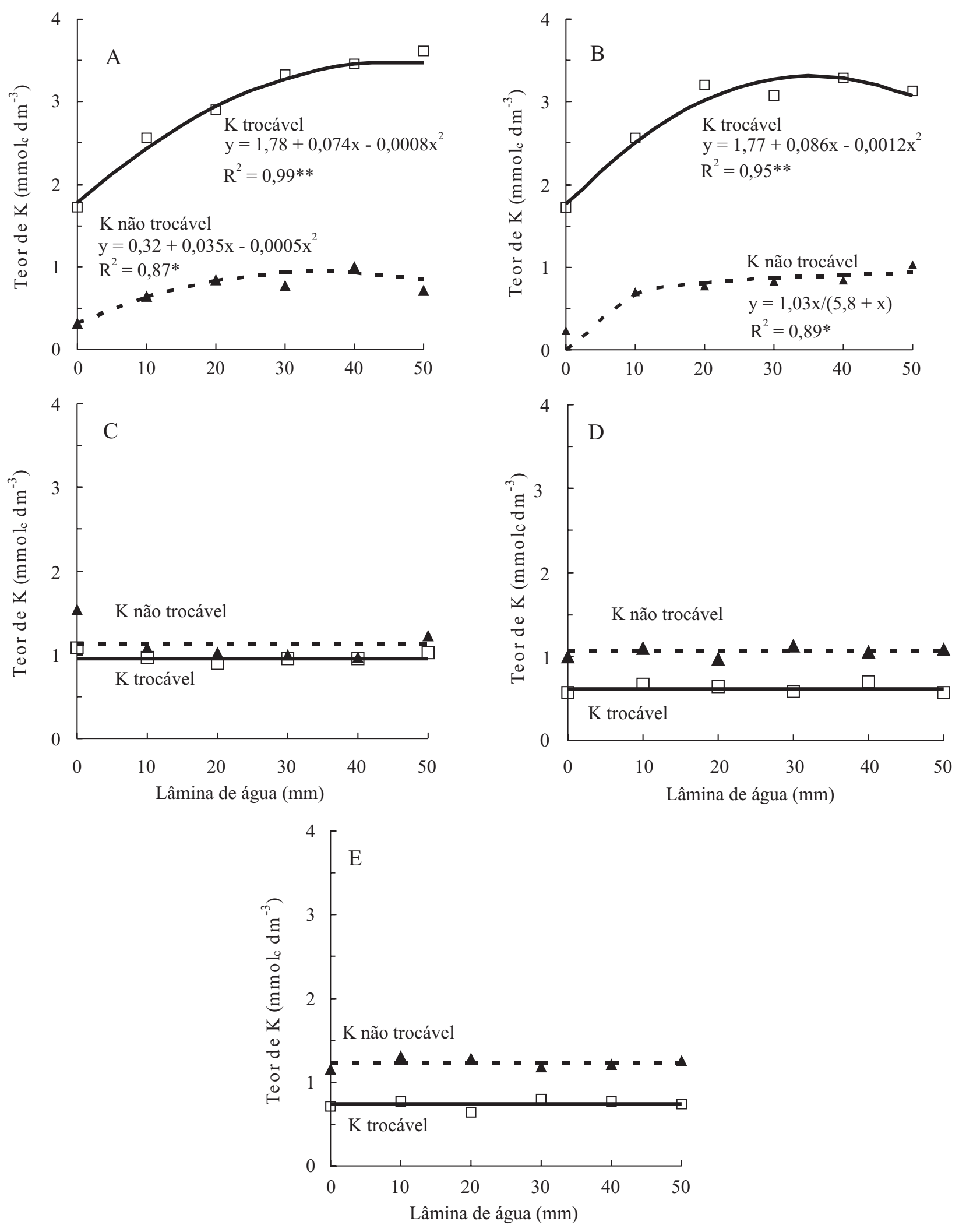

Figura 2. Teores de potássio trocável e não trocável no solo, resultantes da lâmina de água aplicada como chuva simulada sobre a palha de milheto, nas profundidades de 0-2 m (A), 2-4 cm (B), 4-8 cm (C), 8-16 cm (D) e 16-32 cm (E), na ausência de adubação potássica. * e **Significativo a 5 e $1 \%$ de probabilidade, respectivamente. 

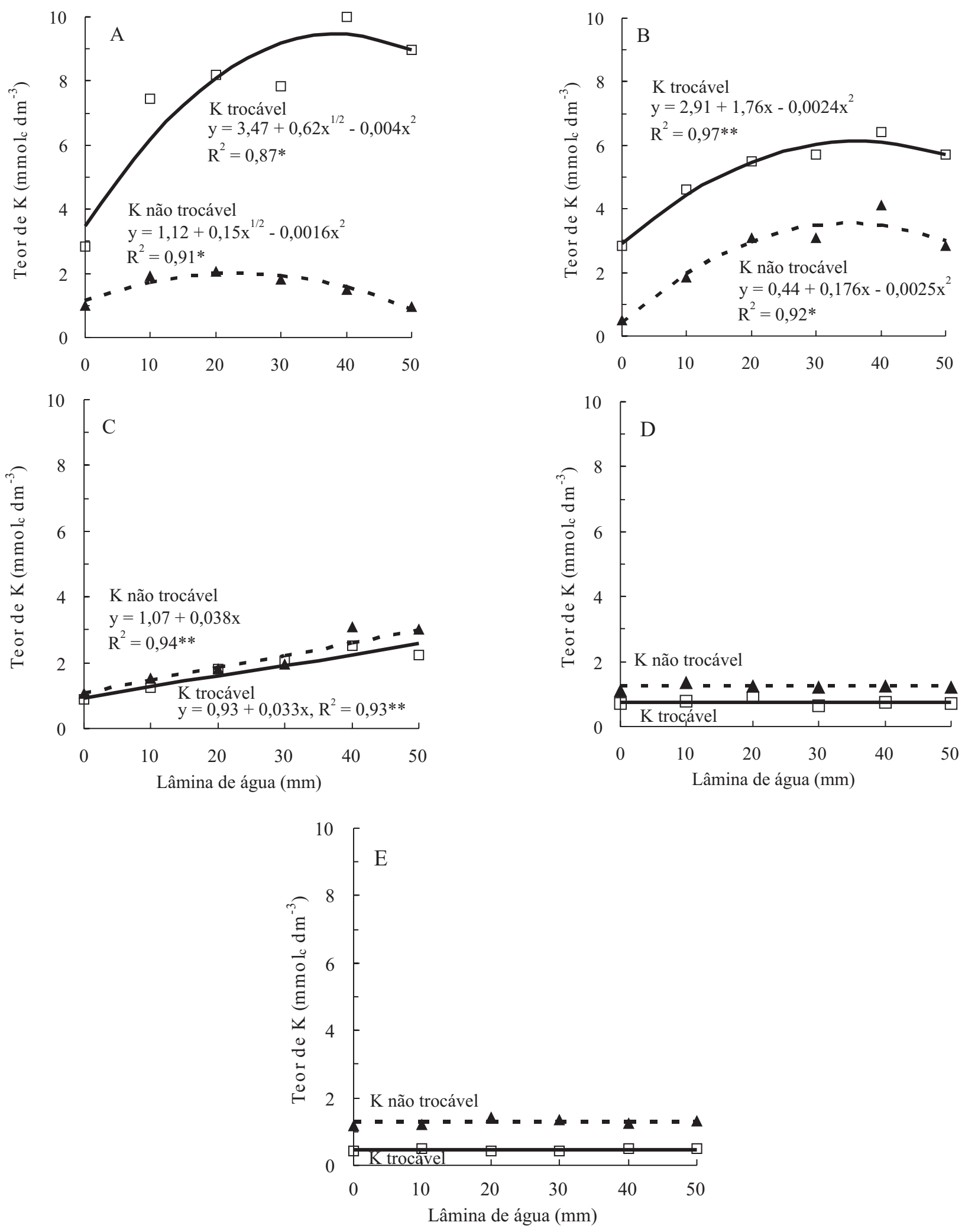

Figura 3. Teores de potássio trocável e não trocável no solo, resultantes da lâmina de água aplicada como chuva simulada sobre a palha de milheto, nas profundidades de 0-2 cm (A), 2-4 cm (B), 4-8 cm (C), 8-16 cm (D) e 16-32 cm (E), na presença de adubação potássica. * e**Significativo a 5 e $1 \%$ de probabilidade, respectivamente. 


\section{Conclusões}

1. A palha do milheto, mesmo sem adubação potássica, é fonte importante de $\mathrm{K}$, que é lixiviado até $4 \mathrm{~cm}$ de profundidade por chuvas superiores a $30 \mathrm{~mm}$.

2. A lixiviação de $\mathrm{K}$ em profundidade no solo é proporcional à chuva aplicada, entretanto, uma chuva de $50 \mathrm{~mm}$ não carreia o nutriente para abaixo de $8 \mathrm{~cm}$.

3. A passagem de K trocável para não trocável é rápida, pois tanto o K lixiviado da palha de milheto quanto do adubo proporcionam aumento dos teores de K não trocável.

\section{Referências}

CARVALHO, W.A.; ESPÍNDOLA, C.R.; PACCOLA, A.A. Levantamento de solos da Fazenda Lageado - Estação Experimental "Presidente Médici”. Botucatu: Faculdade de Ciências Agronômicas, Universidade Estadual Paulista, 1983. 95p. (Boletim técnico, 1)

EMBRAPA. Centro Nacional de Pesquisa de Solos (Rio de Janeiro, RJ). Manual de métodos de análise de solo. 2.ed. Rio de Janeiro, 1997. 212p.

EMBRAPA. Centro Nacional de Pesquisa de Solos (Rio de Janeiro, RJ). Sistema Brasileiro de classificação de solos. Rio de Janeiro, 1999. 412p.

FRANCHINI, J.C.; MIYAZAWA, M.; PAVAN, M.A.; MALAVOLTA, E. Dinâmica de íons em solo ácido lixiviado com extratos de resíduos de adubos verdes e soluções puras de ácidos orgânicos. Pesquisa Agropecuária Brasileira, v.34, p.2267-2276, 1999.

KLEPKER, D.; ANGHINONI, I. Características físicas e químicas do solo afetadas por métodos de preparo e modos de adubação. Revista Brasileira de Ciência do Solo, v.19, p.395-401, 1995.

KNUDSEN, D.; DETERSON, G.A.; PRATT, P.F. Lithium, sodium and potassium. In: KLUTE, A.; PAGE, A.L. (Ed.). Methods of soil analysis. $2^{\text {nd }}$ ed. Madison: American Society of Agronomy, 1982. v.2, p.225-246. (Agronomy, 9).

MALAVOLTA, E.A.; VITTI, G.C.; OLIVEIRA, S.A. Avaliação do estado nutricional das plantas: princípios e aplicações. Piracicaba: Potafos, 1997. 201p.
MARSCHNER, H. Functions of mineral nutrients: macronutrients. In: MARSCHNER, H. Mineral nutrition of higher plants. ${ }^{\text {nd }}$ ed. London: Academic Press, 1995. p.231-255.

MISCHAN, M.M.; PINHO, S.Z. Experimentação agronômica: dados não balanceados. Botucatu: Fundibio, 1996. 456p.

RAIJ, B. van; ANDRADE, J.C. de; CANTARELLA, H.; QUAGGIO, J.A. (Ed.). Análise química para avaliação da fertilidade de solos tropicais. Campinas: IAC, 2001. 285p.

RAIJ, B. van; CANTARELA, H.; QUAGGIO, J.A.; FURLANI, A.M.C. Recomendações de adubação e calagem para o Estado de São Paulo. 2.ed. Campinas: Instituto Agronômico, Fundação IAC, 1996. 285p.

ROSOLEM, C.A.; BESSA, A.M.; PEREIRA, H.F.M. Dinâmica do potássio no solo e nutrição potássica da soja. Pesquisa Agropecuária Brasileira, v.28, p.1045-1054, 1993.

ROSOLEM, C.A.; CALONEGO, J.C.; FOLONI, J.S.S. Lixiviação de potássio da palha de coberturas de solo em função da quantidade de chuva recebida. Revista Brasileira de Ciência do Solo, v.27, p.355-362, 2003.

ROSOLEM, C.A.; CALONEGO, J.C.; FOLONI, J.S.S. Potassium leaching from millet straw as affected by rainfall and potassium rates. Communications in Soil Science and Plant Analysis, v.36, p.1063-1074, 2005.

ROSOLEM, C.A.; NAKAGAWA, J. Residual and annual potassic fertilization for soybeans. Nutrient Cycling in Agroecosystems, v.59, p.143-149, 2001.

SILVA, J.E. da; RITCHEY, K.D. Acumulação diferencial de potássio em oxissolos devido a lavagem do nutriente das plantas de milho para o solo. Revista Brasileira de Ciência do solo, v.6, p.183188, 1982.

SILVA, M.A. de S. Depósitos de calda de pulverização no solo e em plantas de tiririca (Cyperus rotundus L.) em diferentes condições de aplicação. 2000. 57p. Tese (Doutorado) - Universidade Estadual Paulista, Botucatu.

SPARKS, D.L.; HUANG, P.M. Physical chemistry of soil potassium. In: MUNSON, R.D. (Ed.). Potassium in agriculture. Madison: American Society of Agronomy, 1985. p.201-276.

ZIGLIO, C.M.; MIYAZAWA, M.; PAVAN, M.A. Formas orgânicas e inorgânicas de mobilização do cálcio no solo. Brazilian Archives of Biology and Technology, v.42, p.257-262, 1999. 